Original article

Red Beetroot Thematic Issue

\title{
Red Beetroot Juice Phytochemicals Bioaccessibility: an In Vitro Approach
}

\author{
Ivelina Desseva ${ }^{*}$, Magdalena Stoyanova ${ }^{1}$, Nadezhda Petkova ${ }^{2}$, Dasha Mihaylova ${ }^{3}$
}

\author{
'Department of Analytical Chemistry and Physical Chemistry, University of Food Technologies, 26 Maritza Blvd., Plovdiv, Bulgaria \\ ${ }^{2}$ Department of Organic Chemistry and Inorganic Chemistry, University of Food Technologies, 26 Maritza Blvd., Plovdiv, Bulgaria \\ ${ }^{3}$ Department of Biotechnology, University of Food Technologies, 26 Maritza Blvd., Plovdiv, Bulgaria
}

Key words: red beetroot juice, antioxidant activity, bioaccessibility, in vitro digestion, phytonutrients, HPLC

Beetroot, the cultivated form of Beta vulgaris subsp. vulgaris, is known for its various beneficial properties but more critical data about its bioactive compounds digestion is needed. In the present research, the bioaccessibility of phytochemicals in freshly prepared red beetroot juice was studied. Changes in total phenolics content, total flavonoids content, contents of betacyanins and betaxanthins, phenolic acids profile as well as the antioxidant activity were monitored before and after simulated gastrointestinal digestion. Several parameters that provide interrelated information about food quality were additionally evaluated, including oxalic acid and individual sugars content, total titratable acidity, and acetylcholinesterase inhibitory activity. Significant loss of contents of total phenolics and flavonoids measured after digestion resulted in the recovery of 27.07 and $36.4 \%$, respectively. The same negative tendency was observed for betalains bioaccessibility. While nearly $27 \%$ of betaxanthins were present after the simulated digestion, almost all betacyanins (96.07\%) have been lost. The HPLC analysis of phenolic acids of beetroot juice revealed the presence of chlorogenic, caffeic, $p$-coumaric, and sinapic acids. After digestion, a 2.5-fold higher concentration of chlorogenic acid was found, however caffeic and $p$-coumaric acids were no longer detected. The results concerning the antioxidant activity of digested juice were inexplicit. According to the DPPH assay, there was a complete recovery of antioxidant activity, while no activity was detected employing the ABTS assay. Following the cupric ion reducing antioxidant capacity (CUPRAC) and ferric-reducing antioxidant power (FRAP), approximately half of the initial activity was retained. Despite the losses, red beetroot remains a valuable source of biologically active substances. Better understanding of their transformation during digestion is further needed.

\section{LIST OF ABBREVIATIONS}

ABTS - 2,2'-azino-bis(3-ethylbenzothiazoline-6-sulfonic acid); AchE - acetylcholinesterase; ATCI - acetylthiocholine; $\mathrm{BJ}$-beetrootjuice; CUPRAC - cupric ion reducing antioxidant capacity; DAD - diode-array detection; DPPH - 2,2-diphenyl-1-picrylhydrazyl;DTNB-5,5'-dithiobis(2-nitrobenzoicacid); $\mathrm{dw}$ - dry weight; FRAP - ferric-reducing antioxidant power; HPLC - high performance liquid chromatography; MW - molecular weight; PBS - phosphate-buffered saline; SGD - simulated gastrointestinal digestion; SGF - simulated gastric fluid; SIF - simulated intestinal fluid; TE - Trolox equivalent; TEAC - Trolox equivalent antioxidant capacity; TFC - total flavonoid content; TPC - total phenolics content.

\section{INTRODUCTION}

Beetroot (or red beet) is the cultivated form of Beta vulgaris subsp. vulgaris (conditiva) grown throughout the Americas, Europe, and Asia. Unlike Beta vulgaris subsp. vulgaris (altissima), known as sugar beet, conditiva subspecies are two times poorer in sucrose [Wruss et al., 2015]. Red beet is a root veg-

\footnotetext{
* Corresponding Author: Tel.: +359 886947242 .

E-mail: ivelina_hristova_vn@abv.bg (I. Desseva)
}

etable and known as a source of phenolic compounds, carotenoids, nitrates, vitamins, minerals and water-soluble pigments [Chhikara et al., 2019]. It is consumed regularly as part of an everyday diet and also is extensively used as a food coloring agent (E162) [Georgiev et al., 2010]. Red beetroot has gained popularity owing to its biological activity and potential utility as a health-promoting and disease-preventing functional food [Clifford et al., 2015]. Its intense red color is due to the presence of highly reactive nitrogen-containing pigments called betalains. They represent plant secondary metabolites that share some similar chemical properties, biological functions, and color spectrums with anthocyanins but these two groups of metabolites never coexist together in plants [Solovchenko et al., 2018]. Betalains are a class of betalamic acid derivatives which are composed of betacyanins (red-violet colored substances) and betaxanthins (yellow-orange colored substances) [Gandía-Herrero et al., 2010]. Betalains are considered to induce extremely powerful antiradical and antioxidant effects [Gandía-Herrero et al., 2010]. In addition, many studies with laboratory animals demonstrated tumor-chemopreventive effects of red beetroot extracts [Kapadia \& Rao, 2013]. Beetroot is also a rich source of phenolic acids and flavonoids as well as of other compounds, such as carotenoids and ascorbic acid, which may further increase its total antioxidant capacity [Clifford et al., 2015; Wootton-Beard \& Ryan, 2011]. 
Till recently, not many studies have been focused on the transformations that occur during food digestion. This is a complex process with many factors involved. So far, in vivo studies are not an option due to higher experimental cost and serious ethical considerations [Sengul et al., 2014]. Therefore, more and more efforts are put into the development of reliable methods for in vitro gastrointestinal digestion evaluation [Minekus et al., 2014]. Although, in vitro methods have serious disadvantages, they can serve as preliminary test for the bioaccessibility and bioavailability of compounds from the food matrix and as a starting point for further investigations.

Several studies are available so far for beetroot phytochemicals digestibility [Dalmau et al., 2019; Guldiken et al., 2016; Tesoriere et al., 2008]. The processing method and the interactions with the food matrix are considered as the two external factors that significantly influence the actual bioaccessibility and bioavailability of ingested phenolics [Shahidi \& Peng, 2018]. Overall, a limited recovery for different beetroot products is reported that could be moderated by the pretreatment conditions [Dalmau et al., 2019; Guldiken et al., 2016]. So far, a lack of critical data about beetroot juice digestibility is noticeable.

In this regard, the aim of the current study was to evaluate the bioaccessibility of phytochemicals in freshly prepared beetroot juice (BJ) by using in vitro model simulating gastrointestinal digestion (SGD). No extraction method was applied in order to simulate real conditions of juice consumption. The loss of phytochemicals and their corresponding activity and/or recovery of such were also calculated. HPLC-DAD analysis of individual polyphenols, before and after SGD, was performed as well.

\section{MATERIALS AND METHODS}

\section{Chemicals and instruments}

The red beetroot used in this study was with Bulgarian origin (Plovdiv region), vintage 2018. The beetroot juice was purchased from a local fresh fruit juice shop where it was freshly cold-pressed on a slow-turn juicer. The BJ was then immediately subjected to analysis. Three independent samples were made and tested from the same beet material and the results are presented as mean. Simulated gastric fluid (SGF) and simulated intestinal fluid (SIF) were prepared as described by Minekus et al. [2014].

All reagents used in this study were of analytical grade and purchased from Merck Chemicals (Germany) and Sigma-Aldrich (Germany).

All spectrophotometric measurements were performed on SPECTROstar Nano Microplate Reader (BMG LABTECH, Ortenberg, Germany), and all HPLC assays were performed on Elite LaChrome (Hitachi, Tokyo, Japan) HPLC system equipped with DAD and ELITE LaCHrome (Hitachi, Tokyo, Japan) software.

\section{In vitro gastrointestinal digestion procedure}

The assay was performed according to the procedures described by Minekus et al. [2014] with minor modifications. Only gastric and intestinal phase were included.

\section{Gastric phase}

BJ (5 mL) was mixed with $3.62 \mathrm{~mL}$ of a porcine pepsin stock solution (pepsin from porcine gastric mucosa, P7000, Sigma-Aldrich; $5520 \mathrm{U} / \mathrm{mL}$ made up in SGF electrolyte stock solution), $2.5 \mu \mathrm{L}$ of $0.3 \mathrm{M} \mathrm{CaCl}_{2}$ and $132 \mu \mathrm{L}$ of phospholipids $(0.17 \mathrm{mM}$ in the final digestion mixture). The $\mathrm{pH}$ of the mixture was corrected with $1 \mathrm{M} \mathrm{HCl}$ to the value of 3.0 and the volume of the mixture was made up to $10 \mathrm{~mL}$ with distilled water. The mixture was then incubated at $37^{\circ} \mathrm{C}$ with constant shaking in a shaking water bath for $2 \mathrm{~h}$. The $\mathrm{pH}$ was regularly checked and re-adjusted with $1 \mathrm{M} \mathrm{HCl}$ when needed.

\section{Intestinal phase}

Gastric chyme $(10 \mathrm{~mL})$ was mixed with $8 \mathrm{~mL}$ of a pancreatin solution (pancreatin from porcine pancreas, P1750, Sigma-Aldrich; $1.72 \mathrm{U} / \mathrm{mL}$ made up in SIF electrolyte stock solution based on trypsin activity), $1.9 \mathrm{~mL}$ of fresh bile extract (160 mM fresh bile salts in final mixture, Sigma-Aldrich), $20 \mu \mathrm{L}$ of $0.3 \mathrm{M} \mathrm{CaCl}_{2}, 1 \mathrm{M} \mathrm{NaOH}$ to reach $\mathrm{pH} 7.0$, and water to $20 \mathrm{~mL}$ total volume. The mixture was then incubated at $37^{\circ} \mathrm{C}$ in a shaking water bath for $2 \mathrm{~h}$. The $\mathrm{pH}$ was regularly checked and re-adjusted with $1 \mathrm{M} \mathrm{NaOH}$ during the process, if needed.

For the blank sample, water was used instead of BJ. The values obtained for blanks were subtracted from the sample values for each analysis. The digestion sample was then centrifuged and stored at $-20^{\circ} \mathrm{C}$ till further analysis, but no longer than for 7 days.

\section{Moisture}

Total moisture content of the samples was determined in a moisture analyzer balance (Radwag PMC 50/NH, Poland). The sample was placed in a dish and dried to constant mass at $105^{\circ} \mathrm{C}$.

\section{Total titratable acidity}

The titratable acidity was measured by titration with a $0.1 \mathrm{M} \mathrm{NaOH}$. The results are expressed as g citric acid in $100 \mathrm{~mL}$ juice as follows:

$$
\begin{gathered}
\mathrm{TA}, \mathrm{g} / 100 \mathrm{~mL}=\mathrm{N}_{\mathrm{NaOH}} \times \mathrm{V}_{\mathrm{NaOH}} \times \mathrm{M}_{\mathrm{eq}}(\text { citric acid }) \\
\times \mathrm{DF} \times 100 / 1000 / \mathrm{V}_{\text {sample }}
\end{gathered}
$$

where: $\mathrm{N}_{\mathrm{NaOH}}$ is the normal concentration of $\mathrm{NaOH}, \mathrm{mol} / \mathrm{L}$; $\mathrm{V}_{\mathrm{NaOH}}$ is the volume of $\mathrm{NaOH}$ required to reach the equivalent point, $\mathrm{mL}, \mathrm{M}_{\mathrm{eq}}$ (citric acid) is the equivalent weight of citric acid $(64.04 \mathrm{~g} / \mathrm{eq}), \mathrm{DF}$ is the dilution factor, and $\mathrm{V}_{\text {sample }}$ is the volume of $\mathrm{BJ}, \mathrm{mL}$.

\section{Oxalic acid content determination}

Oxalic acid content was determined as described by Wruss et al. [2015] without modifications using the permanganese reduction method. Beetroot juice was diluted $(1: 10, v / v)$ with $\mathrm{H}_{2} \mathrm{O}$, and $2 \mathrm{~mL}$ of the diluted sample was mixed with $6 \mathrm{~mL}$ of $\mathrm{H}_{2} \mathrm{O}$ and $1 \mathrm{~mL}$ of $1 \mathrm{M} \mathrm{H}_{2} \mathrm{SO}_{4}$. The sample was heated to $50-60^{\circ} \mathrm{C}$ and titrated with a $0.02 \mathrm{M} \mathrm{KMnO}_{4}$ solution until persisting pale pink appeared. The concentration of oxalic acid was determined using a reference curve generated 
by pure oxalic acid $\left(5-50 \mathrm{mg} / \mathrm{mL}, \mathrm{R}^{2}=0.9987\right)$ and expressed as mg per g of dry weight (dw) of BJ (mg/g dw). All samples were measured in triplicate.

\section{Determination of total phenolics content}

The total phenolics content (TPC) was analyzed using the method of Singleton \& Rossi [1965] with some modifications. Native or digested BJ $(0.1 \mathrm{~mL})$ was mixed with $0.5 \mathrm{~mL}$ of the Folin-Ciocalteu reagent and $0.4 \mathrm{~mL}$ of $7.5 \% \mathrm{Na}_{2} \mathrm{CO}_{3}$. The mixture was vortexed and left at $50^{\circ} \mathrm{C}$ for $5 \mathrm{~min}$. After incubation, the absorbance was measured at $765 \mathrm{~nm}$. The TPC was expressed as mg gallic acid equivalents (GAE) per $\mathrm{g}$ of native or digested BJ dw (mg $\mathrm{GAE} / \mathrm{g} \mathrm{dw}$ ). The linear range for gallic acid standard was $5-100 \mathrm{mg} / \mathrm{L}\left(\mathrm{R}^{2}=0.9965\right)$

\section{Determination of total flavonoids content}

The total flavonoids content (TFC) was evaluated according to a modified method described by Park et al. [1997]. An aliquot of $0.5 \mathrm{~mL}$ of the native or digested BJ was added to $0.1 \mathrm{~mL}$ of $10 \% \mathrm{Al}\left(\mathrm{NO}_{3}\right)_{3}, 0.1 \mathrm{~mL}$ of $1 \mathrm{M}$ $\mathrm{CH}_{3} \mathrm{COOK}$, and $3.8 \mathrm{~mL}$ of ethanol. After incubation at ambient temperature for $40 \mathrm{~min}$, the absorbance was measured at $415 \mathrm{~nm}$. Quercetin was used as a standard in the linear range of $5-80 \mu \mathrm{g} / \mathrm{mL}\left(\mathrm{R}^{2}=0.9972\right)$ and the results were expressed as $\mu \mathrm{g}$ quercetin equivalents (QE) per $\mathrm{g}$ of $\mathrm{dw}$ of sample ( $\mu \mathrm{g} \mathrm{QE} / \mathrm{g} \mathrm{dw})$.

\section{Spectrophotometric quantification of betalains}

Betalains quantification was performed as described by Stintzing et al. [2003]. Samples of native or digested BJ were diluted with McIlvaine buffer ( $\mathrm{pH}$ 6.5) to obtain absorption values of $0.9 \leq \mathrm{A} \geq 1.0$ at their respective absorption maxima. The betalain contents (BC), separately for betacyanins and betaxanthins, were calculated as follows:

$$
\mathrm{BC}[\mathrm{mg} / \mathrm{g} \mathrm{dw}]=\mathrm{A} \times \mathrm{DF} \times \mathrm{MW} /(\mathrm{cxlxg})
$$

where: A is the absorption value at the absorption maximum corrected by the absorption at $650 \mathrm{~nm}$, DF is the dilution factor, 1 is the path length $(1 \mathrm{~cm})$ of the cuvette, and $\mathrm{g}$ is the dry weight in $1 \mathrm{~mL}$ of sample. For quantification of betacyanins and betaxanthins, the molecular weights (MW) and molar extinction coefficients $(\varepsilon)$ of betacyanins $(\mathrm{MW}=550 \mathrm{~g} / \mathrm{mol}$; $\varepsilon=60,000 \mathrm{~L} /(\mathrm{mol} / \mathrm{cm})$ in $\left.\mathrm{H}_{2} \mathrm{O} ; \lambda=536 \mathrm{~nm}\right)$ and betaxanthins $\left(\mathrm{MW}=339 \mathrm{~g} / \mathrm{mol} ; \varepsilon=48,000 \mathrm{~L} /(\mathrm{mol} / \mathrm{cm})\right.$ in $\mathrm{H}_{2} \mathrm{O}$; $\lambda=485 \mathrm{~nm}$ ) were applied. All measurements were performed in triplicate.

\section{Determination of antioxidant activity DPPH• scavenging activity}

The ability of the sample to donate an electron and scavenge 2,2-diphenyl-1-picrylhydrazyl (DPPH) radical was determined by the slightly modified method of Brand-Williams et al. [1995]. Freshly prepared $4 \times 10^{-4} \mathrm{M}$ solution of DPPH radicals was mixed with native or digested $\mathrm{BJ}$ in a ratio of 2:0.5 $(v / v)$. The light absorption was measured at $517 \mathrm{~nm}$ after 30-min incubation. The DPPH radical scavenging activity of native or digested BJ was presented as Trolox equivalents
(TE) in the linear range of the standard of $50-500 \mu \mathrm{mol} / \mathrm{L}$ $\left(\mathrm{R}^{2}=0.9985\right)$ and expressed as $\mu \mathrm{mol}$ TE per $\mathrm{g} d w$ of sample ( $\mu \mathrm{mol} \mathrm{TE} / \mathrm{g} \mathrm{dw}$ ).

\section{ABTS $^{\bullet+}$ scavenging activity}

The scavenging activity of the native or digested BJ against 2,2'-azino-bis(3-ethylbenzothiazoline-6-sulfonic acid) radical action $\left(\mathrm{ABTS}^{\bullet+}\right.$ ) was estimated according to Re et al. [1999]. Briefly, $\mathrm{ABTS}^{\cdot+}$ was produced by reacting ABTS stock solution $(7 \mathrm{mM})$ with $2.45 \mathrm{mM}$ potassium persulfate and allowing the mixture to stand in the dark at room temperature for $14 \mathrm{~h}$ before use. Afterward, the $\mathrm{ABTS}^{\cdot+}$ solution was diluted with ethanol to an absorbance of $0.7 \pm 0.02$ at $734 \mathrm{~nm}$ and equilibrated at $30^{\circ} \mathrm{C}$. After the addition of $1.0 \mathrm{~mL}$ of diluted $\mathrm{ABTS}^{\cdot+}$ solution to $0.01 \mathrm{~mL}$ of native or digested $\mathrm{BJ}$, the absorbance reading was taken at $30^{\circ} \mathrm{C}$ after $6 \mathrm{~min}$. The results were expressed as Trolox equivalent antioxidant capacity (TEAC, $\mu \mathrm{mol} \mathrm{TE} / \mathrm{g} \mathrm{dw}$ ) in the linear range of the standard of $500-2000 \mu \mathrm{mol} / \mathrm{L}\left(\mathrm{R}^{2}=0.9966\right)$.

\section{Ferric-reducing antioxidant power}

The ferric-reducing antioxidant power (FRAP) assay was carried out according to the procedure of Benzie \& Strain [1999] with slight modification. The FRAP reagent was prepared fresh daily and was warmed to $37^{\circ} \mathrm{C}$ prior to use. One hundred and fifty microliters of the native or digested BJ were allowed to react with $2850 \mu \mathrm{L}$ of the FRAP reagent at $37^{\circ} \mathrm{C}$ for $4 \mathrm{~min}$. The absorbance was recorded at $593 \mathrm{~nm}$ and the results were expressed as Trolox equivalents ( $\mu \mathrm{mol} \mathrm{TE} / \mathrm{g}$ $\mathrm{dw})$ in the linear range of the standard of $50-500 \mu \mathrm{mol} / \mathrm{L}$ $\left(\mathrm{R}^{2}=0.9970\right)$.

\section{Cupric ion reducing antioxidant capacity (CUPRAC) assay}

The CUPRAC assay was carried out according to the procedure of Apak et al. [2004]. One $\mathrm{mL}$ of $\mathrm{CuCl}_{2}$ solution $(1.0 \times$ $10^{-2} \mathrm{M}$ ) was mixed with $1 \mathrm{~mL}$ of neocuproine methanolic solution $\left(7.5 \times 10^{-3} \mathrm{M}\right), 1 \mathrm{~mL} \mathrm{NH}_{4}$ Ac buffer solution $(\mathrm{pH} 7.0)$, and $0.1 \mathrm{~mL}$ of the native or digested $\mathrm{BJ}$ followed by addition of $1 \mathrm{~mL}$ water (total volume $=4.1 \mathrm{~mL}$ ), and mixed well. Absorbance against a reagent blank was measured at $450 \mathrm{~nm}$ after $30 \mathrm{~min}$. Trolox was used as a standard in the linear range of $200-2000 \mu \mathrm{mol} / \mathrm{L}\left(\mathrm{R}^{2}=0.9929\right)$ and the results were expressed as $\mu \mathrm{mol} \mathrm{TE} / \mathrm{g} \mathrm{dw}$.

\section{Acetylcholinesterase (AChE) inhibitory assay}

The experimental conditions of the AChE assay were based on the method described by Lobbens et al. [2017] with slight modifications. The acetylcholinesterase inhibitory assay was carried out in a 96-welled microplate. Each well contained $30 \mu \mathrm{L}$ of AChE (final concentration of $0.05 \mathrm{U} / \mathrm{mL}$ ), $125 \mu \mathrm{L}$

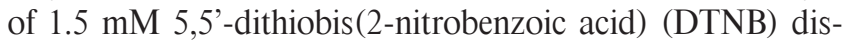

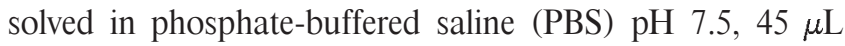
of PBS pH 7.5, and $25 \mu \mathrm{L}$ of test solution or $25 \mu \mathrm{L}$ negative control (water). A blank sample was prepared by adding buffer instead of enzyme. The microplate was shaken for $10 \mathrm{~s}$ and made to $30^{\circ} \mathrm{C}$ for $5 \mathrm{~min}$. Hereafter, $30 \mu \mathrm{L}$ of $7.5 \mathrm{mM}$ acetylthiocholine (ATCI) dissolved in water were added to each well and the absorbance was measured every $30 \mathrm{~s}$ for $1 \mathrm{~min}$ at $412 \mathrm{~nm}$. The blank corrected data were plotted 
against time and the reaction rate (the slope of the plot) was calculated. Last, the inhibition was calculated by comparing the reaction rate in the test solution compared to the negative control. The experiment was performed in triplicate. The inhibition express in percentages as follows:

$$
\% \text { inhibition }=100-\left(\text { Slope }_{\text {sample }} / \text { Slope }_{\text {negative control }}\right) \times 100
$$

\section{HPLC analysis of phenolic acids}

HPLC separation of the BJ phenolic acids was performed on Supelco Discovery HS C18 column $(5 \mu \mathrm{m}, 250 \times 4.6 \mathrm{~mm}$, Sigma-Aldrich, St. Louis, USA), operated at $30^{\circ} \mathrm{C}$ under gradient conditions with mobile phase consisting of $2 \%(\mathrm{v} / \mathrm{v})$ acetic acid (solvent A) and acetonitrile (solvent B) as reported by Mihaylova et al. [2019]. The samples were filtered thought $0.45 \mu \mathrm{m}$ syringe filter (polytetrafluoroethylene filter) and $20 \mu \mathrm{L}$ were injected into the system. The gradient program used was: $0-1 \mathrm{~min}-95 \% \mathrm{~A}$ and 5\% B; $1-40 \mathrm{~min}$ : $50 \% \mathrm{~A}$ and $50 \% \mathrm{~B}$; 40-45 min: $100 \%$ B; 46-50 min: 95\% A and 5\% B. The detection of chlorogenic, caffeic, $p$-coumaric, and sinapic acids was carried out at $320 \mathrm{~nm}$ in the linear range of $10-100 \mu \mathrm{g} / \mathrm{mL}$ for all the standards. The corresponding correlation coefficients were $0.9986,0.9983,0.9900$, and 1.0000 , respectively. The identification was done by comparing the retention time of the compound and those of the corresponding standard. The flow rate was $0.8 \mathrm{~mL} / \mathrm{min}$. The results were expressed in $\mu \mathrm{g} / \mathrm{g} \mathrm{dw}$.

\section{HPLC analysis of sugars}

Chromatographic separations and determination of BJ sugars were performed on an Elite Chrome Hitachi HPLC system, coupled with a Chromaster 5450 refractive index detector (RID). The separation was done on a Shodex ${ }^{\circledR}$ Sugar SP0810 $(7 \mu \mathrm{m}, 300 \times 8.0 \mathrm{~mm}$, Tokyo, Japan $)$ and a guard column Shodex SP - G $(5 \mu \mathrm{m}, 50 \times 6 \mathrm{~mm})$ operating at $85^{\circ} \mathrm{C}$, mobile phase $\mathrm{H}_{2} \mathrm{O}$ with flow rate $1.0 \mathrm{~mL} / \mathrm{min}$ and the injection volume of $20 \mu \mathrm{L}$ as described by Petkova et al. [2014]. The detection of sucrose, glucose, and fructose was performed in the linear range of $0.5-10 \mathrm{mg} / \mathrm{mL}$ and the corresponding correlation coefficients were $0.9988,0.9985$, and 0.9995 , respectively. The results were calculated as $\mathrm{g} / 100 \mathrm{~g} \mathrm{dw}$, the identification was done by comparing the retention time of the compound and those of the corresponding standard.

\section{Statistical analysis}

All tests were carried out in triplicate and the results were presented as mean \pm standard deviation (SD) using Microsoft Excel 2010.

\section{RESULTS AND DISCUSSION}

\section{Analysis prior to digestion}

Freshly cold pressed red beetroot juice was subjected to several analyses prior to digestion. The results for moisture content, $\mathrm{pH}$, and titratable acidity of the juice are presented in Table 1 . These parameters provide interrelated information about food quality. Oxalic acid content was also determined, because beetroot was considered as naturally rich in oxalic acid - 400 $-600 \mathrm{mg} / 100 \mathrm{~g}$ fresh weight (fw) [Duke, 2000]. This compound
TABLE 1. Chemical composition, $\mathrm{pH}$ value, and total titratable acidity of beetroot juice prior to digestion.

\begin{tabular}{lc}
\hline Parameter & Value \\
\hline Moisture $(\mathrm{g} / 100 \mathrm{~mL})$ & $92.86 \pm 0.12$ \\
$\mathrm{pH}$ & $6.35 \pm 0.01$ \\
Total titratable acidity $(\mathrm{g} / 100 \mathrm{~mL})$ & $0.24 \pm 0.03$ \\
Oxalic acid $(\mathrm{mg} / \mathrm{g} \mathrm{dw})$ & $224.8 \pm 1.2$ \\
TPC $(\mathrm{mg} \mathrm{GAE} / \mathrm{g} \mathrm{dw})$ & $30.81 \pm 2.96$ \\
TFC ( $\mu \mathrm{g}$ QE/g dw) & $6.72 \pm 0.16$ \\
Betacyanins $(\mathrm{mg} / \mathrm{g} \mathrm{dw})$ & $2.81 \pm 0.10$ \\
Betaxanthins $(\mathrm{mg} / \mathrm{g} \mathrm{dw}$ & $1.27 \pm 0.00$ \\
Sucrose $(\mathrm{g} / 100 \mathrm{~g} \mathrm{dw})$ & $7.20 \pm 0.15$ \\
Glucose $(\mathrm{g} / 100 \mathrm{~g} \mathrm{dw})$ & $3.14 \pm 0.22$ \\
Fructose $(\mathrm{g} / 100 \mathrm{~g} \mathrm{dw})$ & $4.06 \pm 0.25$ \\
\hline
\end{tabular}

TPC, total phenolics content; TFC, total flavonoids content; GAE, gallic acid equivalent; $\mathrm{QE}$, quercetin equivalent.

is a strong metal ion chelator leading however to the formation of kidney stones [Holmes \& Assimos, 2004]. In our study, oxalic acid concentration was $224.8 \mathrm{mg} / \mathrm{g}$ dw of BJ.

To red beetroots are attributed numerous health benefits, associated to their wide-ranging array of bioactive molecules. The presence of phytochemicals has most often been explored. Although recommendations for the daily intake of phenolics and other antioxidants have not yet been well defined, it is considered that their consumption is beneficial for human health [Karametal., 2018; Mihaylovaetal., 2018]. The BJ tested in this study showed a significant TPC - $30.81 \mathrm{mg}$ GAE/g dw (Table 1). Vasconcellos et al. [2016] obtained $3.67 \mathrm{mg} \mathrm{GAE} / \mathrm{g} \mathrm{dw}$, which is approximately 8 times lower than reported here. In other studies, TPC in BJ was reported to be $0.52 \mathrm{mg} \mathrm{GAE} / \mathrm{mL}$ [Porto et al., 2017] and $0.98 \mathrm{mg} \mathrm{GAE} / \mathrm{mL}$ [Wootton-Beard \& Ryan, 2011], which is respectively 4 and 2 times lower compared to our results (data not shown).

Flavonoids, which are part of the phenolic compound family, have an important contribution to the overall antioxidant activity of a given simple. That is why their content is also evaluated. In the present study, significantly lower TFC of BJ was measured, i.e. $6.72 \mu \mathrm{g} \mathrm{QE} / \mathrm{g} \mathrm{dw}$ (Table 1). In other studies, $83.34 \mathrm{mg} \mathrm{QE} / \mathrm{g}$ and $0.42 \mathrm{mg} \mathrm{QE} / \mathrm{g}$ total flavonoid contents of fresh beetroot juice were reported [da Silva et al., 2016; Olumese \& Oboh, 2016]. This difference is likely due to the various origins of the beetroot material, including the various climatic and agricultural growth conditions.

Many fruits and vegetables have been reported to possess acetylcholinesterase inhibitory activity, making them useful for consumption by Alzheimer's patients [Szwajgier \& Borowiec, 2012]. In the accessible literature there is a lack of information about the presence or not of this activity in beetroot. Solely, Murthy \& Manchali [2013] stated in their review that red beetroot possesses anti-acetylcholinesterase activity. In our study no inhibition in the beetroot juice was detected. 
TABLE 2. Antioxidant and acetylcholinesterase (AchE) inhibitory activities of beetroot juice.

\begin{tabular}{|c|c|}
\hline Activity & Value \\
\hline $\begin{array}{l}\mathrm{DPPH}^{\bullet} \text { scavenging activity } \\
(\mu \mathrm{mol} \mathrm{TE} / \mathrm{g} \mathrm{dw})\end{array}$ & $56.71 \pm 1.66$ \\
\hline $\begin{array}{l}\mathrm{ABTS}^{\bullet+} \text { scavenging activity } \\
(\mu \mathrm{mol} \mathrm{TE} / \mathrm{g} \mathrm{dw})\end{array}$ & $97.04 \pm 1.35$ \\
\hline FRAP ( $\mu \mathrm{mol}$ TE/g dw) & $184.74 \pm 2.62$ \\
\hline CUPRAC ( $\mu \mathrm{mol} \mathrm{TE} / \mathrm{g} \mathrm{dw})$ & $222.84 \pm 2.35$ \\
\hline AChE inhibitory activity (\%) & n.d. \\
\hline
\end{tabular}

DPPH', 2,2-diphenyl-1-picrylhydrazyl radical, ABTS •+, 2,2'-azino-bis(3ethylbenzothiazoline-6-sulfonic acid) radical action; FRAP, ferric-reducing antioxidant power; CUPRAC, cupric ion reducing antioxidant capacity; TE, Trolox equivalent, n.d., not detected.

The antioxidant capacity of BJ is strongly linked to the content of red pigments. Based on their results, Czapski et al. [2009] considered that primarily betalains as responsible for the antioxidant capacity of red beets, therefore, they are probably the most studied beetroot phytochemicals. In this study, contents of betacyanins and betaxanthins were determined spectrophotometrically (Table 1). Content of betacyanins, the red pigments, was 2.2 times higher than that of betaxanthins, the yellow pigments, resulting to a ratio of 1:0.45. The betalain content is thought to be influenced by many factors, such as the size of roots, cultivar, climatic and agricultural conditions [Bazaria \& Kumar, 2016]. Moreover, the extraction method is critical for their determination. Carrillo et al. [2017] demonstrated that betalains seemed to be largely responsible for the total antioxidant capacity found in the insoluble fraction, which could explain the lower values in this study. Kujala et al. [2002] reported slightly higher pigment contents in flesh of different red beet cultivars (4.4 to $9.2 \mathrm{mg} / \mathrm{g} \mathrm{dw}$ ) that are still comparable to the betalains content reported in our study $(4.08 \mathrm{mg} / \mathrm{g} \mathrm{dw})$.

Beetroot has relatively sweet taste, so the determination of its sugars content is of particular interest. In this regard, contents of individual sugars (sucrose, glucose, and fructose) of BJ were evaluated and data are presented in Table 1. Although red beetroot is poorer in sugars than sugar beet, sucrose is still the main sugar followed by glucose and fructose [Bavec et al., 2010]. The BJ sucrose content found in this study was $7.20 \mathrm{~g} / 100 \mathrm{~g} \mathrm{dw}$, which is in agreement with a previous study reported by Wruss et al. [2015]. The same author however indicated much lower glucose and fructose content $(0.41 \%$ in total) than these cited here $(3.14$ and $4.06 \mathrm{~g} / 100 \mathrm{~g}$ dw, respectively).

The antioxidant activity of plant materials is related to their natural self-defense mechanisms. Different in vitro methods are used in order to evaluate the strength of this activity. They are designed to imitate the antioxidant action that phytochemicals exercise in vivo. The most commonly used assays for the reducing potential evaluation are FRAP and CUPRAC while the anti-radical scavenging activity is studied according to DPPH and ABTS assays [Haida \& Hakiman, 2019]. Red beet belongs to the group of 10 vegetables of the highest antioxidant potential [Wettasinghe et al., 2002]. The results of the antioxidant potential assay of red beetroot juice are presented in Table 2. Granato et al. [2015] reported $6363 \mu \mathrm{mol}$ $\mathrm{TE} / \mathrm{L}$ according to DPPH assay which is 0.64 times higher than that obtained in this study $(4048 \pm 120 \mu \mathrm{mol} \mathrm{TE} / \mathrm{L})$. The same author reported average activity towards CUPRAC of $17664 \mu \mathrm{mol} \mathrm{TE} / \mathrm{L}$, which is comparable to our result by the same method (data not shown). The antioxidant potential of the juice toward the ABTS ${ }^{*}+$ was evaluated to be $97.04 \mu \mathrm{mol} \mathrm{TE} / \mathrm{g} \mathrm{dw}$. The reducing potential according to FRAP assay was measured to be $184.74 \mu \mathrm{mol} \mathrm{TE} / \mathrm{g} \mathrm{dw}$ compared to Ou et al. [2002] that reported values from 12 to $120 \mu \mathrm{mol} \mathrm{TE} / \mathrm{g} \mathrm{dw}$ of beetroots of different varieties.

\section{In vitro gastrointestinal digestion of beetroot juice}

Once entered into a human body food is subjected to digestion. This is a complex, multistage process that has its general rules but remains specific to each individual. That is why it is not easy to imitate digestion entirely in a laboratory setting; however, efforts are being made to determine the conditions closest to the human body [Minekus et al., 2014]. Although this process begins in the human mouth, in our study this step is omitted because of the liquid form of the sample, which is usually not chewed and passes directly into the stomach and small intestines afterwards. Food bioaccessibility

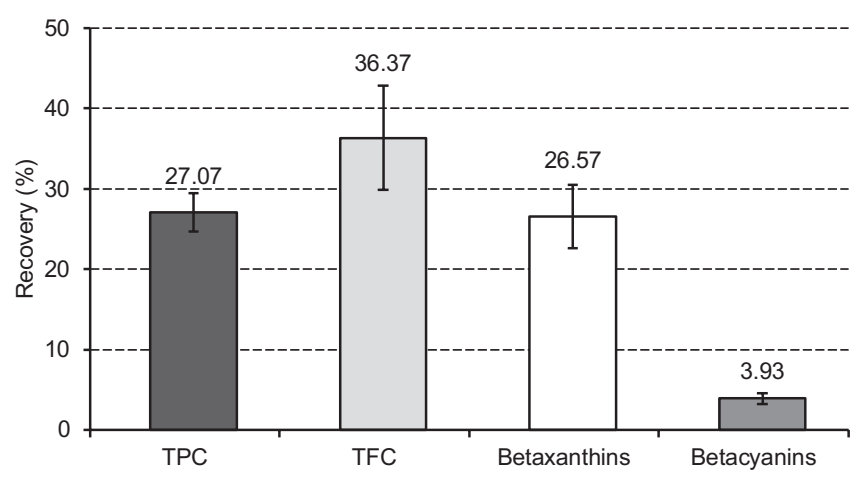

FIGURE 1. Recovery of total phenolics content (TPC), total flavonoids content (TFC), and contents of betaxanthins and betacyanins after in $v i$ tro simulated gastrointestinal digestion (SGD) of red beetroot juice.

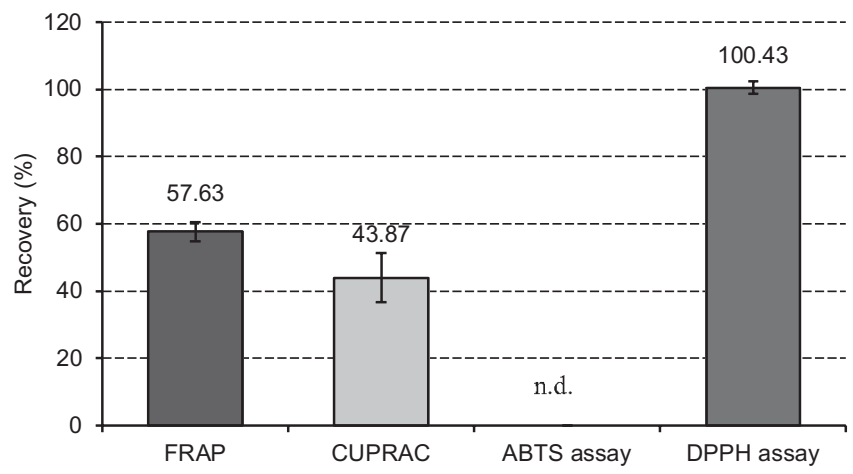

FIGURE 2. Recovery of antioxidant activity after in vitro simulating gastrointestinal digestion (SGD) of red beetroot juice.

n.d., not detected; FRAP, ferric-reducing antioxidant power; CUPRAC, cupric ion reducing antioxidant capacity; ABTS - 2,2'-azino-bis(3-ethylbenzothiazoline-6-sulfonic acid) radical cation; DPPH - (2,2-diphenyl1-picryl-hydrazyl-hydrate) free radical. 
TABLE 3. Contents of individual phenolic acids in beetroot juice before and after simulated gastrointestinal digestion (SGD) ( $\mu \mathrm{g} / \mathrm{g} \mathrm{dw}$ ).

\begin{tabular}{l|c|c}
\hline Phenolic acid & Before SGD & After SGD \\
\hline Chlorogenic acid & $16.99 \pm 0.55$ & $42.42 \pm 1.02$ \\
Caffeic acid & $22.21 \pm 0.75$ & n.d. \\
$p$-Coumaric acid & $52.69 \pm 0.98$ & n.d. \\
Sinapic acid & $19.86 \pm 0.80$ & $16.15 \pm 0.77$ \\
\hline
\end{tabular}

$\mathrm{dw}$ - dry weight, n.d. - not detected.

(the amount of released soluble food components which are ready for intestinal absorption) is among the most important factors determining the bioavailability [Parada \& Aguilera, 2007].

Digestion of phytochemicals is a complex process, and their bioaccessibility depends on both the characteristics of the food matrix and the physiological conditions throughout the digestion [Alminger et al., 2014]. Since phenolic phytochemicals are very different in their chemical structure and properties, this leads to their different bioaccessibility. In the present study, the bioaccessibility was evaluated by determining the total phenolic and flavonoid contents, betaxanthin and betacyanin contents as well as the remaining antioxidant activity after digestion of BJ. Figure 1 presents the data for the recovery of contents of total phenolics, total flavonoids, and betalains after SGD. Loss of $72.93 \%$ of total phenolics and $63.63 \%$ of total flavonoids was reported. Much lower recovery was claimed by Guldiken et al. [2016], only $5.0 \%$ for TPC and $10.0 \%$ for TFC. Significant reduction of TPC was also reported by Bouayed et al. [2011] and Pavan et al. [2014] in the analysis of different apple varieties and araticum and papaya extracts submitted to SGD. Flavonoids loss during digestion of red chiltepin was established by Ovando-Martinez et al. [2018]. The same negative tendency was observed for betalains bioaccessibility. While nearly $27 \%$ of betaxanthins were present after the simulated digestion, almost all betacyanins (96.07\%) have been lost. Our results are in agreement with the findings of Sawicki et al. [2019], who also noticed betalain content reduction during the in vitro digestion. Betalains are very sensitive compounds that are degraded by high temperature, oxygen, light, $\mathrm{pH}$ changes, and enzyme activity [Ravichandran et al., 2013]. Although, both betacyanins and betaxanthins have a broad $\mathrm{pH}$ stability in the $\mathrm{pH}$ range of 3.0-7.0, a loss of their content after digestion is reported [Tesoriere et al., 2008] probably due to isomerization, decarboxylation, and/or cleavage that may occur [Stitzing \& Carle, 2004].

Figure 2 presents the data for antioxidant activity recovery after in vitro SGD. The resulted antioxidant activity of digested juice varied across the four methods. No activity was detected according to the ABTS assay while full recovery was measured by the DPPH assay. Following the CUPRAC and FRAP, approximately half of the initial activity remained after digestion. Guldiken et al. [2016] also reported varied results about the antioxidant activity of digested red beetroot juice. They claimed no remaining activity based on the DPPH assay, with $0.4 \%, 8 \%$, and $24 \%$ recovery determined with CUPRAC, FRAP, and ABTS assays, respectively. Although all four are electron transfer-based assays [Apak et al., 2007], some factors like: radical formation and stability, sample solubility in reaction media, affinity against the sample components etc., could make the difference in the results. In addition, it should be taken into account that despite the both radicals are synthetic; the reaction temperature and light conditions are completely different. DPPH radical is stabilized by itself, while ABTS cation radical has to be formed initially. During digestion, many reactions occurs leading to the inactivation of some active molecules or liberation of others from the matrix [Pavan et al., 2014]. The presence of bile acids should also be taken into account. That is why variations are expected in the remaining antioxidant activity.

The HPLC analysis of phenolic acids of native red beetroot juice revealed the presence of chlorogenic, caffeic, $p$ coumaric, and sinapic acids at contents of 16.99, 22.21, 52.69, and $19.86 \mu \mathrm{g} / \mathrm{g} \mathrm{dw}$, respectively (Table 3). Caffeic and $p$-coumaric acids were no longer detected after the digestion process. Interestingly, 2.5 times higher concentration of chlorogenic acid was measured in the digested sample. Sinapic acid's bioaccessibility remained at $16.15 \mu \mathrm{g} / \mathrm{g} \mathrm{dw}$, which represented $81 \%$ recovery.

Various research papers reported changes in the phenolic acids content after the digestion process. Loss in the sinapic acid of $H$. cannabinus L. was reported by Wong et al. [2014]. Decrease of chlorogenic acid content after SGD of various fruits was previously claimed as well [Bouayed et al., 2012], however reports on the stability of this acid during digestion also exist [Correa-Betanzo et al., 2014]. Moreover, Bermúdez-Soto et al. [2007] also reported $28 \%$ increase of chlorogenic acid content after digestion of chokeberry (Aronia melanocar$\mathrm{pa}$ ) probably due to isomerisation reactions of neochlorogenic acid, whereas Ovando-Martínez et al. [2018] reported low bioaccessibility values of caffeic and $p$-coumaric acids in red chiltepin attributed to the gastrointestinal conditions. Therefore, further investigations on interactions between food components during digestion are needed.

\section{CONCLUSIONS}

Beta vulgaris (red beetroot) is consumed worldwide due to its high nutritive and medicinal values. Many studies have been focused on pre-treated beet products but data on the bioavailability of fresh juice phytochemicals are still limited. In this regard, in the present study the phytochemicals content and the antioxidant activity of freshly prepared beetroot juice were evaluated. It was demonstrated that this vegetable juice could be assumed as a valuable source of biologically active compounds such as phenolics (including flavonoids and phenolic acids) and betalains. Furthermore, the bioaccessibility of the phytochemicals was determined to assess the potential benefits of juice consumption. In conclusion, the SGD process resulted in lower recovery of total phenolics, total flavonoids, and betalains. The remaining antioxidant activity measured by four in vitro methods was variable. Digestion process led to a higher content of chlorogenic acid but decreased concentrations of caffeic, $p$-coumaric, and sinapic 
acids. In this regards, further studies on different component interactions during digestion process are needed in order to better understand the potential health benefits of food.

\section{RESEARCH FUNDING}

The authors gratefully acknowledge the financial support of the University of Food Technologies' Scientific Research Fund, project 03/19-H.

\section{CONFLICT OF INTERESTS}

The authors declare no conflict of interest.

\section{REFERENCES}

1. Alminger, M., Aura, A.-M., Bohn, T., Dufour, C., El, S.N., Gomes, A., Karakaya, S., Martínez-Cuesta, M.C., McDougall, G.J., Requena, T., Santos, C.N. (2014). In vitro models for studying secondary plant metabolite digestion and bioaccessibility. Comprehensive Reviews in Food Science and Food Safety, 13(4), 413-436.

2. Apak, R., Güçlü, K., Özyürek, M., Karademir, E. (2004). Novel total antioxidant capacity index for dietary polyphenols and vitamins $\mathrm{C}$ and $\mathrm{E}$, using their cupric ion reducing capability in the presence of neocuproine: CUPRAC method. Journal of Agricultural and Food Chemistry, 52(26), 7970-7981.

3. Apak, R., Güçlü, K., Demirata, B., Özyürek, M., Çelik, S.E., Bektaşoğlu, B., Berker, K.I., Özyurt, D. (2007). Comparative evaluation of various total antioxidant capacity assays applied to phenolic compounds with the CUPRAC assay. Molecules, 12 (7), 1496-1547.

4. Bavec, M., Turinek, M., Grobelnik-Mlakar, S., Slatnar, A., Bavec, F. (2010). Influence of industrial and alternative farming systems on contents of sugars, organic acids, total phenolic content, and the antioxidant activity of red beet (Beta vulgaris L. ssp. vulgaris Rote Kugel). Journal of Agricultural and Food Chemistry, 58(22), 11825-11831.

5. Bazaria, B., Kumar, P. (2016). Compositional changes in functional attributes of vacuum concentrated beetroot juice. Journal of Food Processing and Preservation, 40(6), 1215-1222.

6. Benzie, F., Strain, J. (1999). Ferric reducing/antioxidant power assay: Direct measure of total antioxidant activity of biological fluids and modified version for simultaneous measurement of total antioxidant power and ascorbic acid concentration. Methods in Enzymology, 299, 15- 27.

7. Bermúdez-Soto, M.-J., Tomás-Barberán, F.-A., García-Conesa, M.-T. (2007). Stability of polyphenols in chokeberry (Aronia melanocarpa) subjected to in vitro gastric and pancreatic digestion. Food Chemistry, 102(3), 865-874.

8. Bouayed, J., Deußer, H., Hoffmann, L., Bohn, T. (2012). Bioaccessible and dialysable polyphenols in selected apple varieties following in vitro digestion vs. their native patterns. Food Chemistry, 131(4), 1466-1472.

9. Bouayed, J., Hoffmann, L., Bohn, T. (2011). Total phenolics, flavonoids, anthocyanins and antioxidant activity following simulated gastro-intestinal digestion and dialysis of apple varieties: Bioaccessibility and potential uptake. Food Chemistry, 128(1), $14-21$.
10. Brand-Williams, W., Cuvelier, E., Berset, C. (1995). Use of a free radical method to evaluate antioxidant activity. $L W T-$ Food $S c i$ encce and Technology, 28(1), 25-30.

11. Carrillo, C., Rey, R., Hendrickx, M., Del Mar Cavia, M., Alonso-Torre, S. (2017) Antioxidant capacity of beetroot: Traditional vs novel approaches. Plant Foods for Human Nutrition, 72(3), 266-273.

12. Chhikara, N., Kushwaha, K., Sharma, P., Gat, Y., Panghal, A. (2019). Bioactive compounds of beetroot and utilization in food processing industry: A critical review. Food Chemistry, 272, 192-200.

13. Clifford, T., Howatson, G., West, D.J., Stevenson, E.J. (2015). The potential benefits of red beetroot supplementation in health and disease. Nutrients, 7(4), 2801-2822.

14. Correa-Betanzo, J., Allen-Vercoe, E., McDonald, J., Schroeter, K., Corredig, M., Paliyath, G. (2014). Stability and biological activity of wild blueberry (Vaccinium angustifolium) polyphenols during simulated in vitro gastrointestinal digestion. Food Chemistry, 165, 522-531.

15. Czapski, J., Mikołajczyk, K., Kaczmarek, M. (2009). Relationship between antioxidant capacity of red beet juice and contents of its betalain pigments. Polish Journal of Food and Nutrition Sciences, 59(2), 119-122.

16. Dalmau, M.E., Llabrés, P.J., Eim, V.S., Rosselló. C., Simal, S. (2019). Influence of freezing on the bioaccessibility of beetroot (Beta vulgaris) bioactive compounds during in vitro gastric digestion. Journal of the Science of Food and Agriculture, 99(3), 1055-1065.

17. da Silva, D.V.T., de Oliveira Silva, F., Perrone, D., Pierucci, A.P.T.R., Conte-Junior, C.A., da Silveira Alvares, Th., del Aguila, E.M., Paschoalin, V.M.F. (2016). Physicochemical, nutritional, and sensory analyses of a nitrate-enriched beetroot gel and its effects on plasmatic nitric oxide and blood pressure. Food and $\mathrm{Nu}$ trition Research, 60, art. no. 29909.

18. Duke, J.A. (2000). Handbook of Phytochemical Constituents of GRAS Herbs and Other Economic Plants. 2nd edition. CRC Press Inc., Boca Raton, Florida, USA, p. 404.

19. Gandía-Herrero, F., Escribano, J., García-Carmona, F. (2010). Structural implications on color, fluorescence, and antiradical activity in betalains. Planta, 232(2), 449-460.

20. Georgiev, V.G., Weber, J., Kneschke, E.M., Denev, P.N., Bley, T., Pavlov, A.I. (2010). Antioxidant activity and phenolic content of betalain extracts from intact plants and hairy root cultures of the red beetroot Beta vulgaris cv. Detroit dark red. Plant Foods for Human Nutrition, 65(2), 105-111.

21. Granato, D., Karnopp, A.R., van Ruth, S.M. (2015). Characterization and comparison of phenolic composition, antioxidant capacity and instrumental taste profile of juices from different botanical origins. Journal of the Science of Food and Agriculture, 95(10), 1997-2006.

22. Guldiken, B., Toydemir, T., Memis, K.N., Okur, S., Boyacioglu, D., Capanoglu, E. (2016). Home-processed red beetroot (Beta vulgaris L.) products: Changes in antioxidant properties and bioaccessibility. International Journal of Molecular Sciences, 17(6), art. no. 858 .

23. Haida, Z., Hakiman, M. (2019). A comprehensive review on the determination of enzymatic assay and nonenzymatic antioxidant activities. Food Science and Nutrition, 7(5), 1555-1563.

24. Holmes, R.P., Assimos, D.G. (2004). The impact of dietary oxalate on kidney stone formation. Urological Research, 32(5), 311-316. 
25. Kapadia, G.J., Rao, G.S. (2013). Anticancer effects of red beet pigments. In B. Neelwarne B. (Ed.), Red Beet Biotechnology, Springer, Boston, MA, USA, pp. 132, 140.

26. Karam, J., Bibiloni, M.D.M., Tur, J.A. (2018). Polyphenol estimated intake and dietary sources among older adults from Mallorca Island. PLoS ONE, 13(1), art. no. e0191573.

27. Kujala, T.S., Vienola, M.S., Klika, K.D., Loponen, J.M., Pihlaja, K. (2002). Betalain and phenolic composition of four beetroot (Beta vulgaris) cultivars. European Food Research and Technology, 214(6), 505-510.

28. Lobbens, E.S., Vissing, K.J., Jorgensen, L., de Weert, M., Jäger, A.K. (2017). Screening of plants used in the European traditional medicine to treat memory disorders for acetylcholinesterase inhibitory activity and anti amyloidogenic activity. Journal of Ethnopharmacology, 200, 66-73.

29. Mihaylova, D., Popova, A., Alexieva, I., Krastanov, A., Lante, A. (2018). Polyphenols as suitable control for obesity and diabetes. Open Biotechnology Journal, 12, 219-228.

30. Mihaylova, D., Vrancheva, R., Desseva, I., Ivanov, I., Dincheva, I., Popova, M., Popova, A. (2019). Analysis of the GC-MS of volatile compounds and the phytochemical profile and antioxidant activities of some Bulgarian medicinal plants. Zeitschrift für Naturforschung C - Journal of Biosciences, 74(1-2), 45-54.

31. Minekus, M., Alminger, M., Alvito, P., Ballance, S., Bohn, T., Bourlieu, C., Carriere, F., Boutrou, R., Corredig, M., Dupont, D., Dufour, C., Egger, L., Golding, M., Karakaya, S., Kirkhus, B., le Feunteun, S., Lesmes, U., Macierzanka, A., Mackie, A., Marze, S., McClements, D.J., Ménard, O., Recio, I., Santos, C.N., Singh, R.P., Vegarud, G.E., Wickham, M.S.J., Weitschies, W., Brodkorb, A. (2014). A standardised static in vitro digestion method suitable for food - an international consensus. Food and Function, 5(6), 1113-1124.

32. Murthy, K.N.C., Manchali, S. (2013). Anti-diabetic potentials of red beet pigments and other constituents. In B. Neelwarne (Ed.). Red Beet Biotechnology. Springer, Boston, MA, USA, p. 168.

33. Olumese, F.E., Oboh, H.A. (2016). Antioxidant and antioxidant capacity of raw and processed Nigerian beetroot (Beta vulgaris). Nigerian Journal of Basic and Applied Sciences, 24(1), 35-40.

34. Ou, B., Huang, D., Hampsch-Woodill, M., Flanagan, J.A., Deemer, E.K. (2002). Analysis of antioxidant activities of common vegetables employing oxygen radical absorbance capacity (ORAC) and ferric reducing antioxidant power (FRAP) assays: A comparative study. Journal of Agricultural and Food Chemistry, 50(11), 3122-3128.

35. Ovando-Martínez, M., Gámez-Meza, N., Molina-Domínguez, C.C., Hayano-Kanashiro, C., Medina-Juárez, L.A. (2018). Simulated gastrointestinal digestion, bioaccessibility and antioxidant capacity of polyphenols from red chiltepin (Capsicum anпиит L. var. glabriusculum) grown in Northwest Mexico. Plant Foods for Human Nutrition, 73(2), 116-121.

36. Parada, J., Aguilera, J.M. (2007). Food microstructure affects the bioavailability of several nutrients. Journal of Food Science, 72(2), R21-32.

37. Park, Y.K., Koo, M.H., Ikegaki, M., Contado, J.L. (1997). Comparison of the flavonoid aglycone contents of Apis mellifera propolis from various regions of Brazil. Brazilian Archives of Biology and Technology, 40(1), 97-106.

38. Pavan, V., Sancho, R.A.S., Pastore, G.M. (2014). The effect of in vitro digestion on the antioxidant activity of fruit extracts
(Carica papaya, Artocarpus heterophillus and Annona marcgravii). LWT - Food Science and Technology, 59(2/2), SI, 1247-1251.

39. Petkova, N., Vrancheva, R., Denev, P., Ivanov, I., Pavlov, A. (2014). HPLC-RID method for determination of inulin and fructooligosacharides. Acta Scientifica Naturalis, 1, 99-107.

40. Porto, M.R.A., Okina, V.S., Pimentel, T.C., Prudencio, S.H. (2017). Physicochemical stability, antioxidant activity, and acceptance of beet and orange mixed juice during refrigerated storage. Beverages, 3(3), art no. 36.

41. Ravichandran, K., Saw, N.M.M.T., Mohdaly, A.A.A., Gabr, A.M.M., Kastell, A., Riedel, H., Cai, Zh., Knorr, D., Smetanska, I. (2013). Impact of processing of red beet on betalain content and antioxidant activity. Food Research International, 50(2), 670-675.

42. Re, R., Pellegrini, N., Proteggente, A., Pannala, A., Yang, M., Rice-Evans, C. (1999). Antioxidant activity applying an improved ABTS radical cation decolorization assay. Free Radical Biology and Medicine, 26(9-10), 1231-1237.

43. Sawicki, T., Martinez-Villaluenga, C., Frias, J., Wiczkowski, W, Peñas, E, Bączek, N, Zieliński, H. (2019). The effect of processing and in vitro digestion on the betalain profile and ACE inhibition activity of red beetroot products. Journal of Functional Foods, 55, 229-237.

44. Shahidi, F., Peng, H. (2018). Bioaccessibility and bioavailability of phenolic compounds. Journal of Food Bioactivities, 4, 11-68.

45. Sengul, H., Surek, E., Nilufer Erdil, D. (2014). Investigating the effects of food matrix and food components on bioaccessibility of pomegranate (Punica granatum) phenolics and anthocyanins using an in-vitro gastrointestinal digestion model. Food Research International, 62, 1069-1079.

46. Singleton, V.L., Rossi, J.A. (1965). Colorimetry of total phenolics with phosphomolybdic-phosphotungstic acid reagents. American Journal of Enology and Viticulture, 16, 144-158.

47. Solovchenko, A., Yahia, E., Chen, C. (2018). Pigments. In E. Yahia, A. Carrilo (Eds.), Postharvest Physiology and Biochemistry of Fruits and Vegetables, Woodhead Publishing, pp. 225-252.

48. Stintzing, F.C., Carle, R. (2004). Functional properties of anthocyanins and betalains in plants, food, and in human nutrition. Trends in Food Science and Technology, 15(1), 19-38.

49. Stintzing, F.C., Schieber, A., Carle, R. (2003). Evaluation of colour properties and chemical quality parameters of cactus juices. European Food Research and Technology, 216(4) 303-311.

50. Szwajgier, D., Borowiec, K. (2012). Screening for cholinesterase inhibitors in selected fruits and vegetables. Electronic Journal of Polish Agricultural Universities, 15(2), \#06.

51. Tesoriere, L., Fazzari, M., Angileri, F., Gentile, C., Livrea, M.A. (2008). In vitro digestion of betalainic foods. Stability and bioaccessibility of betaxanthins and betacyanins and antioxidative potential of food digesta. Journal of Agricultural and Food Chemistry, 56(2), 10487-10492.

52. Vasconcellos, J., Conte-Junior, C., Silva, D., Pierucci, A.P., Paschoalin, V., Alvares, T.S. (2016). Comparison of total antioxidant potential, and total phenolic, nitrate, sugar, and organic acid contents in beetroot juice, chips, powder, and cooked beetroot. Food Science and Biotechnology, 25(1), 79-84.

53. Wettasinghe, M., Bolling, B., Plhak, L., Xiao, H., Parkin, K. (2002). Phase II enzyme-inducing and antioxidant activities of beetroot (Beta vulgaris L.) extracts from phenotypes of dif- 
ferent pigmentation. Journal of Agricultural and Food Chemistry, 50(23), 6704-6707.

54. Wong, Y.H., Lau, H.W., Tan, C.P., Long, K., Nyam, K.L. (2014). Binary solvent extraction system and extraction time effects on phenolic antioxidants from kenaf seeds (Hibiscus cannabinus L.) extracted by a pulsed ultrasonic-assisted extraction. The Scientific World Journal, 2014, art. no. 789346.

55. Wootton-Beard, P.C., Ryan, L. (2011). A beetroot juice shot is a significant and convenient source of bioaccessible antioxidants. Journal of Functional Foods, 3(4), 329-334.
56. Wruss, J., Waldenberger, G., Huemer, S., Uygun, P., Lanzerstorfer, P., Muller, U., Hoglinger, O., Weghuber, J. (2015). Compositional characteristics of commercial beetroot products and beetroot juice prepared from seven beetroot varieties grown in Upper Austria. Journal of Food Composition and Analysis, 42, 46-55.

Submitted: 21 August 2019. Revised: 6 November 2019 and 10 January 2020. Accepted: 14 January 2020. Published on-line: 31 January 2020. 